\title{
What Is Pre-Modern Up to? \\ On the Vernacular Writing of Xiao Jianghong's Wu-Nuo Trilogy
}

\author{
LIU Zhuyan ${ }^{1} \&$ LIANG Sixuan ${ }^{2}$ \\ ${ }^{1}$ School of Chinese Language and Literature, Lanzhou University; \\ ${ }^{2}$ College of Arts and Humanities, Sichuan Fine Arts Institute, China
}

Received: July 11, $2021 \quad$ Accepted: November 7, $2021 \quad$ Published: January 31, 2022

To cite this article: LIU Zhuyan \& LIANG Sixuan. (2021). What Is Pre-Modern Up to? On the Vernacular Writing of Xiao Jianghong's Wu-Nuo Trilogy. Asia-Pacific Journal of Humanities and Social Sciences, 1(4), 028-034, DOI: 10. 53789/j. 16530465. 2021. 0104.004

To link to this article: https: //doi. org/10.53789/j. 1653-0465.2021.0104.004

Abstract: The pre-modern factor in Xiao Jianghong's Wu-Nuo Trilogy (Sorcery and Exorcise Trilogy) is a sign of distinguishing between urban and rural areas. It highlights the discordant elements from the city and shows the specificity of the countryside. It provides an imaginative solution to the pre-modern era, sighs with the mysterious death of the characters, and resolves the urban-rural conflict with the way of thinking and lifestyle of returning to old rural homesteads, a psychological healing dose for readers. The essence of pre-modern factors is aesthetic modernity, which demonstrates the resistance of aesthetic modernity. It is attributed to human care at the intersection of modernity and tradition to realize the spiritual value of realist literature.

Keywords: Wu-Nuo Trilogy; pre-modern; rural; aesthetic modernity; urban

Notes on the contributors: LIU Zhuyan is a postgraduate student at Lanzhou University with an academic interest in modern and contemporary Chinese literature. LIANG Sixuan is a postgraduate student at the College of Arts and Humanities, Sichuan Fine Arts Institute with an academic interest in art theory.

\author{
前現代何為 \\ 一一論肖江虹 “巫儺三部曲”的鄉土書寫 \\ 劉竺岩 ${ }^{1}$ 梁思琂 ${ }^{2}$ \\ ${ }^{1}$ 蘭州大學文學院; ${ }^{2}$ 四川美術學院藝術人文學院
}

摘 要: 肖江虹“巫儺三部曲” 中的前現代因素是區分城鄉的標誌, 突出來自城市的不和諧因素, 展現了鄉村的特異
性。它提供了關於前現代的想像性解決方式, 用人物神秘的死亡方式為之歎惋, 以回歸鄉土的思維與生活解決城 
鄉衝突,並療愈讀者心霝。前現代因素的本質是審美現代性,彰顯了審美現代性的抵抗姿態,在現代與傳統的交匯 點上歸於人性關懷,實現了現實主義文學的精神價值。

關鍵詞: “巫㨐三部曲”; 前現代; 鄉土; 審美現代性;城市

\section{引言}

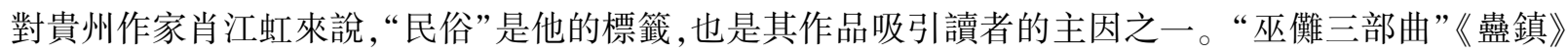
《儺面》與《懸棺》正是其中的集大成者,《儺面》更因斬獲第七屆魯迅文學獎而成為代表作。但作家本人並 不一定認可“民俗”的定位,對於肖江虹來說，“民俗書寫只是他的手段,其目的在於追問現代性進程中人的 命運” (1)。事實上, 在“巫儺三部曲”中, 民俗雖引人矚目, 但僅是作家建構的“前現代世界”之有機組成部分。 在馬克斯 - 韋伯看來, 前現代社會是未祛魅的, “理知化” 與“合理化” 尚未介人,人們相信有神靈存在, 需要 “以魔法支配神靈或向神靈祈求” (2)。在這樣未祛魅的小說世界中, 無論民俗、自然、觀念, 還是圈層結構的人 際關係,都可用“前現代” 概括。要探析作家怎樣觀照“現代性進程中人的命運”,理解與之對立又交融的“前 現代世界” 是必要的。這種前現代作用何在? 怎樣產生意義? 又如何展現作家意圖? 需要在文本內外深人 解讀。

\section{一、前現代是區分城鄉的書寫方式}

《人民文學》為“巫儺三部曲”梳理了一條文學史脈絡, 那就是從沈從文、汪曾祺到王潤滋、李杭育再到肖 江虹的鄉土文化小說之路。如果從文化角度尋繹, 那麼從 “湘西” 到 “尋根” 的路徑, 就讓肖江虹的作品在鄉 土小說中具備了特異性, 即它們很難被歸人 “在鄉” “進城” 與“返鄉” 的新世紀鄉土小說敘事模式 ${ }^{3}$ 。三部 曲中, “在鄉” “進城” 與“返鄉” 是交融混雜的, 既非反思鄉土社會的固有缺陷, 更非對“城” 及其表徵的現代 生活方式的肯定。如果從敘事來看, 城與鄉以對比視角呈現, 前現代是對鄉土的書寫方式, 意圖透視城鄉之 間的區隔。

首先, 肖江虹筆下的鄉村是理想化的, 不和諧因素來自城市。《儺面》中, 帶著一紙診㝴書從城市歸來的 顏素容成了一個“要死的人”。不同于曉蘇《老闆回家》中鄉民嫌貧愛富的戲劇性姿態; 亦非何頓《蒙娜麗莎 的微笑》基於傳統倫理的道德審判, 更非閻連科《柳鄉長》中極具諷刺性的“小姐還鄉” 閙劇。《儺面》中的顔 素容與鄉村的道德、金錢觀念無涉,她是一個來自“城” 的不和諧因素。由於自知將死,她試圖用“惡言相向” “將世間的溫情痛快地殺死” (4) 同時又以“不怕死” 的姿態掩飾內心深處對死亡的恐懼。一方面,由於“進 城” 經歷,她對前現代始終懷有拒斥: “像儺戲這樣的習俗, 早該死去了才是。” 另一方面, 又因恐懼死亡, 請 秦安順為她唱一首“延壽儺”。對於這個“返鄉” 的異類, 無論顔家還是秦安順, 都並未給予道德上的評判。 尤其是秦安順,還以儺戲的方式為她解結, 即消弭罪蒘, 繼而為她延壽, 實際上代表來自鄉土的接納與和解。 儘管 “延壽” 的結果是 “壽已盡”, 但罪怨已然消散 ${ }^{\circledR}$ 。小說的最後, 顏素容拾起秦安順的遺物伏羲氏面具, 更 隱喻著她已不再是“不和諧因素”,經由儺戲,再次融進理想化的鄉村。

與“返鄉者”顏素容不同,純粹的外來者自始至終是與鄉村對立的。城裡來的許淨植以科學原理解釋燕 子峽中的一切, 認為 “我” 看到的幻象是 “恐懼情緒下產生的幻覺” ( ${ }^{8}$ 。許淨植的調查帶來強加于村民的搬遷 計畫。這種在外界看來利於村民的生活方式, 却引來了村民的反感, 其原因有二: “這山旮昌裡頭還睡著祖 宗。”連懸崖都沒一壁,這樣的地頭日子咋過?” ${ }^{8}$ 而將攀岩傳統“改造” 為商業表演的嘗試,也因價值觀的巨 
大差異告終。從中不難看出迥然相異的城鄉思維方式。在這裡, 鄉民展現出來的不是《哦,香雪》中對城的 鄉往,現代化的城市很難對鄉民形成吸引力。因此, 無論作為民俗的儺戲、攀岩,還是建基於“人情” 的人際 關係,既形成區隔城鄉的屏障, 又成為拒絕“外來”的阻力,更是化解城市消極影響的一種有效手段。城鄉間 的二元對立關係就在不和諧因素的應對方式與化解過程中展現。

其次, 前現代因素是凸顯鄉村特異性的手段。它的作用是讓鄉村神秘化, 更讓與之對應的現代城市因而 浮淺。因此, 在三部曲中, 表現民俗等的方式不是巡禮或展示, 而是作為區分城鄉的工具。落實到作品上, 就 是魔幻現實主義方法。三部作品展現的民俗都蘊含著魔幻因素, 且均與 “城” 存在著千絲萬縷的聯繫。《㽬 鎮》中, 趙錦繡委託王昌林製作“情疊”, 是因為進城打工的丈夫王四維與人有染; 《儺面》中, 顏素容請秦安順 用儺戲來解結、延壽, 是因為她在城裡染上了自知命不久矣的疾病; 《懸棺》中, 攀岩本可成為溝通城鄉、帶動 鄉民致富的手段,卻因為民俗本身具有神聖性,鄉民難以接受這種出賣神聖的商業化表演而結束。由此可 見, 在肖江虹筆下, 民俗及其背後根深蒂固的原始思維的一個顯著作用是區分城與鄉, 且被用以化解來自城 市的種種消極影響。而化解這些影響的,也非民俗本身,實為附著在民俗之上的神秘力量。

民俗帶來的神秘力量也只屬於鄉村或鄉村人。《懸棺》中, “我” 在山洞中感到了來自先祖的形象與聲 音。“我”也由此知道了祖先在燕子峽經歷過的殘酷生存史。此外, “我”也曾在即將墜崖時,看見“一隻穿岩 豆藤草鞋的腳” (9), 並因此躲過一劫。但在城裡人看來, 這樣的神奇經歷只用一句 “幻覺” 就可輕易打破, 而這 些神秘力量對城裡人來說, 也並不起作用。《儺面》也是如此。當秦安順為顏素容唱罷一段 “延壽” 儺後, 他 看見了神靈翻冤童子。此時,通過儺戲回歸了鄉土的顏素容也似乎預知了法事的結果。她由 “不信” 到 “信”, 似乎預示著其自身已從城裡回歸了鄉土。因此, 民俗帶來的神秘力量從視角上區分了城鄉。對於鄉 民而言, 神秘力量是常見且不足為怪的; 但對於城裡人,這不僅是他們鄙夷的對象,更是不可見的。以神秘力 量區分城鄉, 並非三部曲首創, 它是鄉土文化小說借鑒魔幻現實主義的一種常見手法, 《白鹿原》即是如此。 在白鹿原上,可以出現法官捉鬼、田小娥顯靈等一系列神秘事件;而當地理空間轉到省城,它們就在趨於現代 化的社會中消失不見了。這與其說是展示了 “震撼人心的藝術力量” “10,冊寧說在城鄉關係中, 作品是以鄉村 為本位的, 二者從根本來講, 是“兩個世界”。神秘力量在城鄉間的起落, 其實蘊含著對城市文明的批判性審 視。

最後, 以前現代因素嚴格區分城鄉, 其實也產生了城市描寫簡單化, 甚至負面化的苗頭。《疊鎮》中, 王 四維與人有染,原因是進城打工難以承受誘惑; 而他留在鄉村的妻子趙錦繡面對王木匠的猛烈追求不為所 動。《儺面》中, 顏素容幼時一直以“懂事” 著稱, 進城經歷不僅讓她重病纏身, 甚至對親友惡語相向。《懸 棺》中, 與城裡聯繫最為密切的來向南違反村規偷盜燕窩, 還試圖將攀岩改造為招攬遊客的商業化項目。從 這樣的視角看, 城市在道德上就走向了負面, 不僅價值觀與傳統鄉土社會相悖, 從倫理上看也不為鄉村所容。 但這個傾向並非三部曲所獨有。早在沈從文那裡, 其城市書寫的弱點就已被學者關注。陸傑在《批判城市, 想像鄉村: 沈從文的都市小說》中指出, 沈從文的城市書寫不具備 “湘西那樣迷人的異國情調”, 除與自然有 關外,無法“和現代情感相關聯”, 因此城市也就僅僅成了一個與正面的鄉村相對立的道德符號 ${ }^{\mathbb{1}}$ 。之所以 讓城市與鄉村在道德上產生對立關係, 關乎作家對現代性的思索。

\section{二、前現代是解決現實問題的想像性手段}

從書寫方式看,前現代因素為三部曲提供了區分城鄉的方式,但其作用不止於此。作為關注現實問題、 觀照人生苦難的作品,作品針對著現實問題, 尤其是關於人的生存困境。但身為審美意識形態的文學無力解 決現實問題, 因此其中的前現代因素, 尤其是基於民俗的神秘力量提供了想像性的解決方式,不僅針對敘事 
的完滿, 更是對讀者的一種心理療愈。較早對文學 “想像性” (imaginary) 進行創造性闆發的是阿爾都塞, 他 認為“意識形態表述了個人與其實在生存條件的想像關係” ${ }^{10}$ 。延續著阿爾都塞,馬歇雷等更認為“看上去沒 有意義的“原始” 文本赤裸裸地表達了意識形態立場。這些意識形態的立場只能形成於物質性的文學文本, 也就是說, 它們只能提供想像, 或者更好的是, 通過想像在意識形態中替代性地解決矛盾” ${ }^{13}$ 。伊格爾頓則整 合了上述觀點, 提出 “文學作品不僅以想像移置了真實, 更把那些 “真實的再現, 塑造成想像性對象的一種生 產, (4) 在三部曲中, 作者正是通過想像移置現實困境, 經由對前現代生活方式與精神氣質的想像, 替代性地 解決城鄉衝突中難以索解的現實困境。

第一, 神秘的死亡方式為前現代的終結唱響了一曲挽歌。《懸棺》中, 燕子峽居民延續數百年的生活方 式終於被城市化浪潮打破。水壩工程讓鄉民不得不走出峽谷, 此時一直夢想著葬身懸棺的二老祖製作了一 對巨大的翅膀, “鷹燕般從高處飛了下去” ${ }^{15}$, 找到了屬於他的懸棺, 以勝利者的姿態完成了 “死亡儀式”, 在 水天一色中飄向遠方。正如作品中屢次出現的 “鷹燕殉崖”, 這隱喻著失去家園後的無所歸依。但對人來 說, 這種 “失去家園” 更多指向前現代生活的終結, 極具儀式性的死亡方式與魔幻色彩的翅膀, 是對舊日生活 的懷戀, 更是藝術性地解決現實困境的方式。

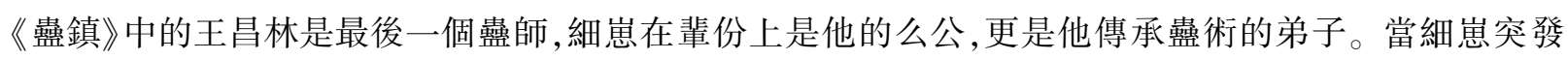
怪病陷人彌留時, 王昌林以一道幻疊, 讓他在幻覺中拽住一掛風筝, “奔跑在那寬闊的廣場上” 10這樣看似 安樂的死亡, 實則昭示㽬的終結。民俗傳承斷絕的困境, 亦即前現代因素的消失, 被隱藏在理想化的、想像性 的死亡背後。《儺面》更是如此, 秦安順以幻覺中的儺戲結束了生命。而他死後兒子們焚燒儺戲家什, 也預 示著儺戲這種勾連生死的傳統儀式之消亡。概言之, 現代性讓“一切堅固的東西都煙消雲散了”, 源自原始 思維的巫術將為科技所取代, 前現代那與世隔絕、自給自足的生活方式終將被打破, 是難以阻擋的歷史洪流。 因此小說以神秘的死亡方式為象徵, 是對傳統消散的想像性解決, 也是一曲面對詩意生活的悠長挽歌。

第二, 回歸鄉土的思維方式與生活方式是對城鄉衝突的想像性解決。《儺面》中的顏素容是城鄉衝突的

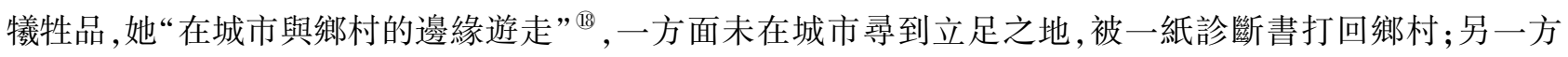
面, 有過進城體驗的顔素容又絕非一個“鄉村人”, 她以“城裡人” 的目光審視儺戲面具, 毫不留情斥之為無用 之物, 又以看似絕情的姿態試圖隔絕親情。儘管作品中的鄉村人並未對其進行道德評判, 避免了使之陷人傳 統與現代道德觀念的兩難困境之中, 但失去了身份認同的顏素容確實成了一個既不被城市接納, 又難以重返 鄉村的“遊魂”。作品給出的解決方式, 是讓她在“延壽儺” 中由 “不信”到“信”, 更“學會了面對死亡, 迎來了 儺面後的神” 19 小說結尾, 顏素容撿起了秦安順的遺物——伏羲氏面具, 表徵著她在思維上回歸了鄉土。 與此同時,她身後傳來了母親的呼喚: “顏素容, 你個砍腦殼的, 天都黑了,還不回家吃飯。” 說明她已回歸了 鄉土的生活方式。

作為承續自沈從文的鄉土文化小說, 三部曲不重在撕裂城市與鄉村, 作者立足鄉村的視角在於對傳統價 值觀的認同, 亦即認同 “一死生, 齊彭殤”之勘破生死, 意圖 “指向生命的另一維度” (ब)。究其實質, 這是一種 回歸內心的想像。無論是《儺面》還是《懸棺》, 作者都清醒意識到, 前現代終將逝去, 被城市化所吞噬。鄉村 尚且自身難保,何況試圖嘗試“回歸鄉土思維方式與生活方式”的人?

第三, 這種想像不僅意圖解決難以直面的社會現實困境, 更是對讀者的一種心理療愈。如果說神秘的死 亡在文本内部解決了傳統式微的焦慮, 那麼回歸鄉土的思維與生活解決的不只是文本, 更針對讀者, 意圖在 心理層面實現重建依賴的文化修復。啟蒙現代性張揚個人主體性, 疏離傳統家庭, 甚至疏離以血緣關係為紐 帶的圈層結構是必然的。對於早已經歷工業化的城市, 這或許可被逐漸接受, 但對鄉村來說, 會給人帶來價 值觀的危機。如吉登斯所論, “當理性的欲求替代了傳統的欲求時, 它們似乎提供了某種比先前的教條更具 有確定性的知識”, 然而現代性在反思中被建構, 這樣確定性的知識 “只不過是一種誤解罷了” 。當城市想 
像被進城經歷擊碎, 顔素容及燕子峽漢子們體驗到幺滅感, 在所難免。這種價值觀也隨之為正在體驗現代性 的讀者所接受, 其共情是可以想見的。因此, 復歸鄉土思維與生活不僅是小說的收束方式, 更將讀者縫合進 文本,用重建依賴帶給他們心理的療愈。

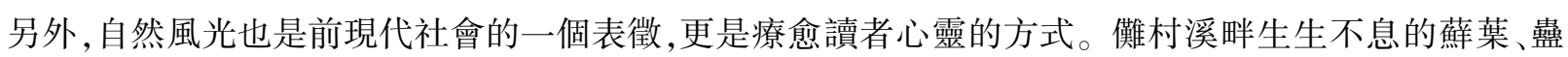
鎮山上能將萬物盡收眼底的山頂開闊地, 乃至燕子峽古怪、凹凸、駭人的峭壁與極富靈性的鷹燕, 構成了理想 化的、隔絕現代的空間。自然與傳統密不可分, 也為文學想像提供了空間。文學史上, 田園牧歌為《赫曼與 犢綠苔》帶來關於理想愛情的浪漫想像; 密西西比河的陌生化景觀賦子《阿達拉》以異域情調的審美體驗, 三 部曲就繼承了浪漫主義文學傳統的審美趣味。如果從現代性層面看, 著重描寫疏離現代生活空間風景的文 學作品, 與治癒系電影是異體同構的。在治癒系電影中, 自然風光“讓被日常瑣屑所包圍的觀眾卸下防備, 跟著故事情節的深人接受進一步的療愈” 3 。正如宮崎駿讓龍貓出現在森林深處, 讓《千與千尋》中的異世界 人口深處人跡罕至的自然之中, 三部曲的自然風光與神秘民俗和情節渾然一體, 其本身更是綜合了地域景觀 與文學想像的治癒空間。

\section{三、前現代的背後還是現代}

如果說前現代只是書寫方式與想像手段, 三部曲就會只有 “魔幻”而失去了 “現實”, 其社會關懷與人文 向度更加無從談起。那麼前現代現象的背後是什麼? 不論是作者的預設還是小說業已實現的現實維度, 它 都指向了審美現代性,一切神秘都是審美現代性的表像。

首先, 前現代現象的背面是審美現代性。肖江虹之所以被歸入沈從文、汪曾祺一脈, 有其依據。沈從文 的創作觀以美為核心。他力圖建設一種 “美和愛的新的宗教”, 以之激發“生命的抽象搜尋”, 乃至 “產生一種 崇高莊嚴感情” 。因而在其湘西小說中, 不見陃習、人性醜惡的表現, 代之以“鄉土人生的道德以及鄉土的 文化、審美意蘊” ${ }^{25}$ 。換言之, 湘西人的前現代生活方式是理想化、審美化了的,真正表現的是現代的審美。 汪曾祺 “尋根” 時期關注風土人情的悠揚韻致,亦複如是。回到肖江虹, 他的作品就承續著這樣的審美觀。 《臯鎮》中, 細崽依照輩分, 是王昌林的么公, 雖因個性頑劣, 常對王昌林惡語相向, 但二人相處之和諧是讀者 無法不承認的。細崽曾在山中救過王昌林, 王昌林對細崽也是疼愛有加。當細崽因怪病死後, 王昌林為他選 好了墓地,他說: “筆架山吧! 那也是我的地頭, 么公和我親, 挨著我吧!”這樣“悲歡一線之間,生死隔牆相 望” 的生命觀, 看似與《生死場》《呼蘭河傳》相似, 但卻擺脫了猛烈的批判性, 取而代之的則是平淡的話語及 其背後的無盡深情。從這個意義上看, 它表徵了周憲所言審美現代性走人的 “昇華了的新感性狀態” 在古 典美與本真性的交融中實現了審美的救贖。

其次,表面上的的前現代彰顯了審美現代性的抵抗姿態。在卡林內斯庫看來,啟蒙現代性與審美現代性 二元對立,在社會歷史的各個領域都體現了分裂與衝突: “一個是理性主義的,另一個若非公然非理性主義, 也是強烈批評理性的; 一個是富有信心和樂觀主義的, 另一個是滿刻懷疑並致力於對信心和樂觀主義進行非 神秘化的。” 三部曲的神秘色彩, 就建立在抨擊理性、信心與樂觀色彩上,這些都潛藏于前現代現象的背後。 如《儺面》中 “解結儺” 消弭罪惡, “延壽儺” 延長壽命, 是在非理性層面對生的信心與樂觀; 《懸棺》中 “我” 對 許淨植的科學解釋並不信服, 甚至在其舉手投足間看出滑稽, 實際也是對理性的一種批評。在與神秘現象相 對立的城市一邊, 城裡人難以理解燕子峽鄉民為何堅持居住在 “不適宜人類居住” 的環境中; 他們審視燕子 峽人攀岩的方式也是娛樂的、理性的, 不帶有其原本具備的神性色彩。在二者的對立衝突中, 雖然《儺面》以 秦安順死前所見的異相, 以及顔素容回歸鄉土告終; 《懸棺》以二老祖飛入懸棺的勝利者姿態收束。但啟蒙 現代性即將吞噬立足審美的鄉村, 仍清晰可辨。作品中現代壓倒傳統, 實則昭示著啟蒙現代性壓倒審美現代 
性。當非理性之物無立錐之地, 社會的現代化意義何在? 這是作者的憂思, 也是作品中審美現代性螳臂當車 般的抵抗性之真義所在。

最後,通過透視作者的審美訴求及其憂思 “巫儺三部曲”的文化取向已然明晰, 且在關於前現代的書寫 中獲得了成功。除了如前所述 “追問現代性進程中人的命運”外,作家的視角尚指向兩個深處。其一是人的 敬畏之心。肖江虹指出, 在《儺面》中, “其實那個幻像只有秦安順一個人可以看到, 因為中國古老的循環時 間概念還在他心裡留存, 他戴上那個面具後看到的可能是他想像的, 但他相信這個東西是存在的, 就是因為 他有怕懼, ${ }^{29}$ 。這是樸素的傳統觀念, 但與作家極力表現的審美現代性並不相悖, 因為二者的共通點是 “拒絕 平庸”,並在此基礎上認同朝向傳統的寬容、歧義和多元。其二, 肖江虹認為當代文學丢掉了文學的莊嚴性, 那就是在敘事倫理意義上 “站在全人類的立場上來寫作” ${ }^{30}$ 。這充分說明,作家強調審美現代性的現實意義, 並未走人唯美主義的頽廢與虛無, 他自始至終以人為中心, 無論人的命運、敬畏之心, 還是敘事倫理立場, 都 具有著強烈的現實關懷。這也與他所理解的現實主義相一致,即關乎人類痛苦與困境的文學均屬現實主義。 這種廣義的現實主義不與浪漫主義對立, 最終指向和解。所以, 作為地方性知識的民俗、風物等可靠與否並 不重要, 它們或許具有相當的文化意義, 但更多是作為手段存在的。由此, 也可以看出作家達成這種由對抗 到和解的努力, 即前文所述的想像性解決。儘管在作品中, 城與鄉一直以二元對立的姿態出現, 但走到作品 的結尾, 都在想像性層面上達成了和解。即便這個和解是不關涉實際解決路徑的, 但于讀者而言, 給出了令 人信服的價值觀,也就實現了文學作為審美意識形態的精神功用。

綜上所述, “巫儺三部曲” 中的前現代因素首先是區分城鄉的書寫方式, 突出了來自城市的不和諧因素, 展現了鄉村的特異性, 但也出現了城市描寫簡單化、負面化的弊端; 其次, 它提供了關於前現代的想像性解決 方式, 用人物神秘的死亡方式為之歎惋, 以回歸鄉土的思維方式與生活方式解決城鄉衝突, 同時, 想像性解決 的對象不僅是難以直面的社會問題, 更是對讀者的心理療愈; 最後, 前現代因素的本質是審美現代性, 它彰顯 了審美現代性的抵抗姿態,並在現代與傳統的交匯點上歸於人性關懷, 實現了現實主義文學的精神價值。

\section{注釋}

(1)18 顔軍:《在城市與鄉村邊緣遊走: 肖江虹小說人物的存在境遇》,《揚子江評論》2018 年第 3 期。

(2) [德] 馬克斯・章伯著, 錢永祥等譯:《學術與政治》, 廣西師範大學出版社 2004 年版, 頁 168 。

(3) 梁波: 《新世紀鄉土小說的“城鄉”價值迷思》, 《蘭州大學學報(社會科學版) 》2010 年第 3 期。

(4)(5)(22) 肖江虹著: 《儺面》, 安徽文藝出版社 2018 年版, 頁 114-182。

(7)(8) 肖江虹著:《儺面》,安徽文藝出版社2018 年版, 頁 217-267。

(10) 治芳: 《略談〈白鹿原〉的魔幻色彩》, 《安徽大學學報》1994 年第 2 期。

(11) JIE Lu. (2010). Critiquing the city, envisioning the country: Shen Congwen's urban fiction. Neohelicon, 1, 359-372.

(12) [法] 路易・阿爾都塞著,顧良譯:《保衛馬克思》, 商務印書館 1984 年版, 頁 142 。

(13) Eagleton, Terry \& Milne, Drew. (1996). Marxist literary theory: a reader. Oxford: Blackwell Publishers.

(14) Eagleton, Terry. (1976). Criticism and ideology: a study in Marxist literary theory. London: Verso.

(15) LIU Huiling. (2021). Research on current situation of rural cultural practice: a case study of villages and towns in Nanyang city, Henan province. Asia-Pacific Journal of Humanities and Social Sciences, 1(3), 77-82.

(16) SHI Xiaomei \& ZHOU Yuxi. (2021). China's international discourse construction: a case study of news reports on China's poverty alleviation. Asia-Pacific Journal of Humanities and Social Sciences, 1(2), 68-77.

(17) [ 美] 馬歇爾 - 伯曼著, 徐大建、張輯譯:《一切堅固的東西都煙消雲散了一一現代性體驗》, 商務印書館 2003 年版, 頁 112 。

(1921) 趙月斌:《來路中的來路肖江虹小說論》,《上海文化》2017 年第 5 期。

(22) [ 英] 安東尼・吉登斯著, 田禾譯:《現代性的後果》,譯林出版社 2011 年版, 頁 34 。 
(23) 劉琨:《自然崇拜・極簡敘事・重建依賴——論日本治癒系類型電影的形式與意義》,《當代電影》2017 年第 11 期。

(24) 沈從文著:《美與愛》,《沈從文文集(第十一捲)》,花城出版社 1984 年版, 頁 379 。

(25) 劉進才:《中國現代文學的審美現代性探寻—以京派作家沈從文、廢名的小說創作為個案》, 《河南大學學報(社會科 學版)》2006 年第 3 期。

(26) 肖江虹著:《儺面》, 安徽文藝出版社 2018 年版, 頁 80-82。

(27) 周害著:《審美現代性批判》, 商務印書館 2005 年版, 頁 163 。

(28) [美] 馬泰 - 卡林內斯庫:《現代性,現代主義,現代化——現代主題的變奏曲》, [美] 馬泰 - 卡林內斯庫著, 顧愛涁、李 瑞華譯:《現代性的五副面孔》, 譯林出版社 2015 年版, 頁 355 。

(29)30 顔軍、肖江虹、尤作勇等: 《民俗書寫與現代世界——肖江虹《儺面》座談會紀要》,《貴州大學學報(社會科學版)》 2017 年第 6 期。

(Editor: JIANG Qing) 